\title{
86807 - MEDO DE CAIR E QUEDAS EM IDOSOS UM ESTUDO LONGITUDINAL
}

\section{Pôster - Gerontologia}

\author{
Priscilla Cardoso da Silva / Silva, PC / UFRGS; Vanessa Dias Possamai / Possamai, VD / UFRGS; \\ Pâmela Andrieli da Silva Tristão / Tristão, PAS / UFRGS
}

O envelhecimento gera modificações físicas, psicológicas e sociais, para além de doenças crônicas e degenerativas que proporcionam agravos de saúde, que muitas vezes contribuem para fatores de risco de quedas ${ }^{1}$. As quedas são consideradas uma das principais causas de morbidades, perda da capacidade funcional, institucionalização e até a morte, no entanto, o medo de cair é outro fator que contribui para diminuição da confiança e potencializa as limitações ${ }^{2}$. Os programas de extensão universitária são uma alternativa para a prática de atividade física para a população idosa que visa uma melhora da qualidade de vida, prevenção de doenças, aumento das capacidades funcionais e independência. $\mathrm{O}$ objetivo do estudo foi comparar o medo de cair e a ocorrência de quedas em idosos participantes de um programa de extensão universitária em atividade física ao longo de quatro anos. A pesquisa caracteriza-se como quase-experimental e longitudinal. A amostra foi composta por 68 idosos, divididos em dois grupos, G1- caidores $(\mathrm{n}=13$, idade média $73,54 \pm 9,22)$, idosos com histórico de quedas e G2-não caidores ( $\mathrm{n}=55$, idade média $69,35 \pm 6,35)$ sem histórico de quedas nos últimos 6 meses. Para comparação das médias utilizou-se o teste $\mathrm{t}$ para amostras dependentes e independentes com índice de significância $(\mathrm{p} \leq 0,05)$ e cálculo de frequência, com o SPSS 21.0 (Comitê de ética no ${ }^{\circ}$ 21.629). Os dados foram coletados através de questionários pré-intervenção (início do ano) e pós-intervenção (final do ano), abrangendo a ocorrência de quedas e o questionário Falls Efficacy Scale Internacional (FES-I), para avaliar o risco de quedas. Foi possível identificar que, quanto ao medo de quedas, houve diferença estatisticamente significante $(p \leq 0,021)$ entre grupos na primeira pré-intervenção (pré-2014), mas essa alteração não se manifestou ao longo dos anos. Em relação ao G1 e G2 no pré-2014 e pós2017, não foi identificada alterações em relação ao medo de quedas, assim mantendo-se ao longo do tempo. Mas foram identificadas as situações que mais aumentaram o medo nos idosos quanto a queda, destacando-se aquelas mais complexas e desafiadoras quanto aos obstáculos externos.

Palavras-chave: Acidentes por quedas, idosos, Estudos longitudinais.

Referência: 1. BRASIL, MINISTÉRIO DA SAÚDE. Anexo1: Protocolo Prevenção de Quedas. Elaborados por PROQUALIS, 2013; 2. MALINI, F. et al. Medo de quedas em idosos: uma revisão de literatura. Revista HUPE: 2014; 13(2), p. 38-44. 